\title{
Stabilized Controller Design for Attitude and Altitude Controlling of Quad-Rotor Under Disturbance and Noisy Conditions
}

\author{
M. Hassan Tanveer, S. Faiz Ahmed, \\ D. Hazry, Faizan A. Warsi and M. Kamran Joyo \\ Centre of Excellence for Unmanned Aerial Systems (COEUAS), School of Mechatronics, \\ University Malaysia Perlis, Jalan Kangar Alor-setar 01000, Kangar Perlis, Malaysia
}

Received 2013-05-27, Revised 2013-06-06; Accepted 2013-07-09

\begin{abstract}
This article presents a control approach to obtain the better stabilization in attitude and altitude of quad-rotor under different disturbance conditions. In the standard Quad-rotor rotor type UAV, controlling of attitude and altitude is one of the most critical tasks and appropriate controller for stabilization of UAV is essential and necessary. These two controls under various conditions of disturbances was a field of research stimulating for the researchers. The controller proposed is contingent on the PID feedback structure with Extended Kalman Filter (EKF). From Lyapunov Stability Theorem, it is proved that quad-rotor proposed altitude control system is asymptotic as well exponentially stability. Extended Kalman Filter (EKF) is used to filter out the sensors and system noises. Finally, the simulations carried out on MATLAB and the result proved the effectiveness of proposed recommended method for stabilization of attitude and altitude of quad-rotor.
\end{abstract}

Keywords: Quad-rotor, Takeoff/Landing and Altitude Control, PID, Lyapunov Stability Theorem, Extended Kalman Filter

\section{INTRODUCTION}

In the last decade, with the increase in technology the demand of unmanned aerial systems has rapidly increased. This is mainly because of the UAVs incredibly carryout a wide range of applications at minimal cost and without endangering any risk to human life. UAVs are inherently suitable for military applications such as Border patrolling, Security Intelligence, cartography, surveillance, cost guards, acquisition of targets. UAVs have also penetrated in civilian applications such as search and rescue missions, explorations, security and surveying of oil pipe lines, Forests on fire, agricultural applications and power and nuclear plants inspection.

The quad-rotor is a famous type of UAV amongst the researchers. The extensive attention towards it is due to its small size, light weight, effortless assembling of the mechanical structure and most importantly their ability to complete the tasks efficiently and autonomously. Its ability to Vertically Take-Off and Land (VTOL) and hovering categorizes it into helicopter UAVs. It is a distinctive type of UAV because of its unique shape and functioning.

With its uniqueness, plenty of technical and distinctive issues are associated to quad-rotor that opened a way to a massive research work. A quadrotor system is a simple structure but nonlinear in nature which makes the controls very complex and difficult. Researchers have been facing issues with controlling the altitude and tackling to the air disturbances while hovering which is the primary concern in this article.

\footnotetext{
Corresponding Author: M. Hassan Tanveer, Centre of Excellence For Unmanned Aerial Systems (COEUAS), School of Mechatronics, University Malaysia Perlis, Jalan Kangar Alor-setar 01000, Kangar Perlis, Malaysia
} 


\subsection{Related Work}

Generally quad-rotor carries several uncertainties, such as air disturbances and mainly due to nonlinearity of the system may remarkably disturb the flight and lead to undesired movement. To avoid these types of movements a suitable control algorithm is required for attitude and altitude control for hover. However In the recent years, altitude and attitude controlling of quadrotor has remained an issue due to the constraints and unstable kinematics and dynamics. Some of the techniques already have been developed for these controls mentioned.

Gotbolt et al. (2013) used Model based PID control for Autopilot design for Helicopter, this article only focused on software framework optimization. The PD control technique was used for tilt rotor UAV stabilization in year 2012 (Chowdhury et al., 2012). In the year 2011 active disturbance rejection controller was proposed by Hua et al. (2011) only for attitude controlling of quad-rotor. H-inf control technique was introduced by Jiao et al. (2010) for trajectory tracking of quad-rotor. Lee et al. (2011) used Dynamic Surface Control (DSC) method for altitude control. This study presents the modeling of a quad-rotor and a technique based on PID controller for altitude and attitude stabilization. Simulation is done on (MATLAB). In a real-time system, sensors and measurement devices provide a noisy data. A filter must be introduced into the system in order to reject noise. Kalman filter might be a decent filter for this system. Since the quad-rotor system is non-linear in nature, an ordinary $\mathrm{KF}$ cannot be used. The extended version of the Kalman filter is extended kalman filter that is specially designed for non-linear systems.

\section{MATERIALS AND METHODS}

\subsection{Modeling of Quad-Rotor}

\subsubsection{Quad-Rotor Kinematics}

UAV quad-rotor comprises of four motor out of which two moves clockwise and remaining two moves anticlockwise as shown in (Fig. 1). Different pairs of propellers attach on the tip of each motor. The rotation of these propellers generate vertical upward lifting force that lifts the quad-rotor body in the air and it can moves in pitch, roll, yaw, hover, take-off and landing positions. These different movements can be achieved by changing the combination and speed of the quadrotor motors described in following section.

To perform hovering, take-off or landing all four propellers rotate with same speed. For take-off the rotation of the propellers must be higher to produce a lifting force greater than the total quad-rotor weight, while for landing, the rotation of the propeller speed gradually decreased to let the quad-rotor getting landed on the ground. The hovering can be achieved by producing the lifting force that equal to the total quad-rotor weight. The relation of the movement can be written as:

$$
\mathrm{U} 1= \pm \omega_{1}^{2} \pm \omega_{2}^{2} \pm \omega_{3}^{2} \pm \omega_{4}^{2}
$$

where, $\omega_{1}{ }^{2}, \omega_{2}{ }^{2} \omega_{3}{ }^{2}, \omega_{4}{ }^{2}$ are angular velocity or propeller speed produced by motor 1, 2, 3 and 4 respectively.

For pitch movement, the speeds of motor 1 and 3 are changed conversely to perform forward and backward movement while other two motors speed must maintain constant to stabilize the quad-rotor. To move forward, the speed of motor M3 must be greater than the speed of motor 1 and vice versa for backward move. The relation of the movement can be written as:

$$
\mathrm{U} 2= \pm \omega_{1}^{2} \mp \omega_{3}^{2}
$$

The method to perform roll movement is same as pith except that in roll movement the speeds of the motor 2 and 4 are changed for right and left movement. The relation of the movement can be written as:

$$
\mathrm{U} 3= \pm \omega_{2}^{2} \mp \omega_{4}^{2}
$$

To perform the yaw movement, the speeds of the motors in pairs (motor 1 and 3 ) and (motor 2 and can be written as:

$$
\mathrm{U} 4= \pm \omega_{1}^{2} \pm \omega_{3}^{2} \mp \omega_{2}^{2} \mp \omega_{4}^{2}
$$

To perform the yaw movement, the speeds of the motors in pairs (motor 1 and 3) and (motor 2 and 4) are changed conversely. To rotate the quad-rotor body to the right, the speeds of motors 2 and 4 must be greater than the speeds of motors 1 and 3 while to rotate it to left, the speed configuration is inverted. The relation of the movement can be written as: 


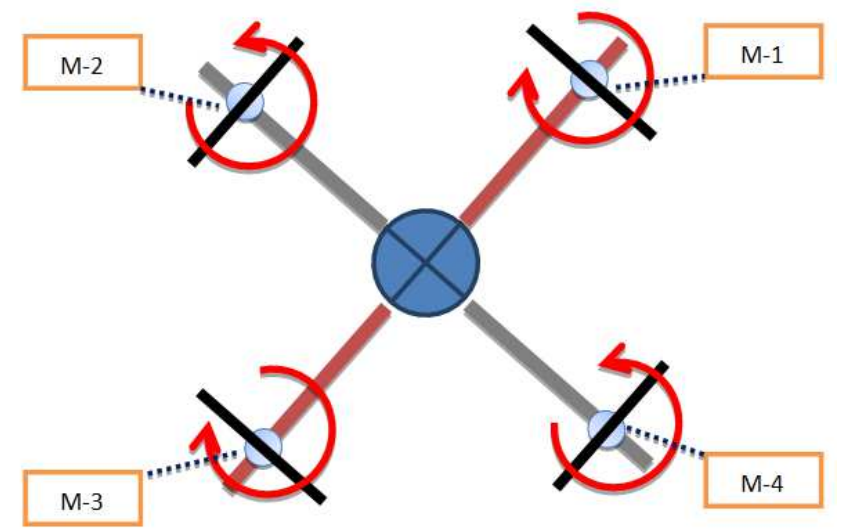

Fig. 1. Quad-rotor UAV with its dimensions

\subsection{Dynamics of Quad-Rotor}

\subsubsection{B.L.D.C. Dynamics}

As discussed earlier that quad-rotor comprises of four motors which are used to control 6 DOF, so we need to understand its motor dynamics. The parameters in Equation (1) can be calculated by geometric, dynamic and aerodynamic evaluation of the mechanic structure:

$$
\dot{\omega}=\mathrm{A}^{\omega}+\mathrm{BV}+\mathrm{C}
$$

where, " $A$ " is the linearized propeller's speed coefficient, " $\mathrm{B}$ " is the linearized input voltage coefficient, "C" is the linearized constant coefficient, " $\omega$ " is the propellers' speed vector, “ $\dot{\omega}$ ”is the propeller's acceleration vector and " $\mathrm{V}$ " is the inputs voltage vector.

The motor with propeller dynamics is identified and validated in (Becker et al., 2012). A first-order transfer function is sufficient to present the dynamics of rotor used in quad-rotor type unmanned systems Equation (2):

$$
G(s)=\frac{0.936}{0.178 S+1}
$$

For determining dynamics of Quad-rotor, we need to understand Earth Inertial frame (E frame) and quadrotor fixed-body frame ( $\mathrm{F}$ frame). The frames are shown in (Fig. 2).

The Quad-rotor orientation $(\phi, \theta, \psi)$ and position (x, y, z) can be defined by Newton Euler Method.

\subsection{Newton-Eular Method}

Newton Euler technique can be used to derive the quad-rotor 6 DOF equation. From the (Fig. 2), two frames earth and body frame have been given. Equation 3 describes the kinematics of a generic 6 DOF rigid body:

$\dot{\xi}=\mathrm{J}_{\Theta}{ }^{\mathrm{V}}$

where, ' $\dot{\xi}$ ' and ' $\mathrm{v}$ ' are generalized velocity vector with respect to E-frame (Earth Fixed Frame) and B-frame (Body Fixed Frame) respectively.

' $\mathrm{J}_{\Theta}$ ' is a generalized matrix.

For quad-rotor linear ' $\Gamma^{\mathrm{E}}$, and angular ' $\Theta$ ' vectors with respect to $E$ frame ' $\xi$ ' and $B$ frame ' $v$ ' can be defined as in Equation (4) and (5) respectively:

$$
\begin{aligned}
& \xi=\left[\Gamma^{\mathrm{E}} \square^{\mathrm{E}}\right]^{\mathrm{T}}=[\mathrm{XYZpqr}]^{\mathrm{T}} \\
& \mathrm{v}=\left[\mathrm{V}^{\mathrm{B}} \omega^{\mathrm{B}}\right]^{\mathrm{T}}=\left[\begin{array}{lll}
\mathrm{u} \mathrm{v} w \theta & \psi
\end{array}\right]^{\mathrm{T}}
\end{aligned}
$$

The rotation $R_{\Theta}$ matrix can be defined according to Equation 6:

$\mathrm{R}_{\Theta}=\left[\begin{array}{ccc}\mathrm{c}_{\psi} \mathrm{c}_{\theta} & -\mathrm{s}_{\psi} \mathrm{c}_{\phi}+\mathrm{c}_{\psi} \mathrm{s}_{\theta} \mathrm{s}_{\phi} & \mathrm{s}_{\psi} \mathrm{s}_{\theta}+\mathrm{c}_{\psi} \mathrm{s}_{\theta} \mathrm{c}_{\phi} \\ \mathrm{s}_{\psi} \mathrm{c}_{\theta} & \mathrm{c}_{\psi} \mathrm{c}_{\phi}+\mathrm{s}_{\psi} \mathrm{s}_{\theta} \mathrm{s}_{\phi}-\mathrm{c}_{\psi} \mathrm{s}_{\phi}+\mathrm{s}_{\psi} \mathrm{s}_{\theta} \mathrm{c}_{\phi} \\ -\mathrm{s}_{\theta} & \mathrm{c}_{\theta} \mathrm{s}_{\phi} & \mathrm{c}_{\theta} \mathrm{c}_{\phi}\end{array}\right]$

Where the notations:

$\mathrm{c}=\cos$

$\mathrm{s}=\sin$ 


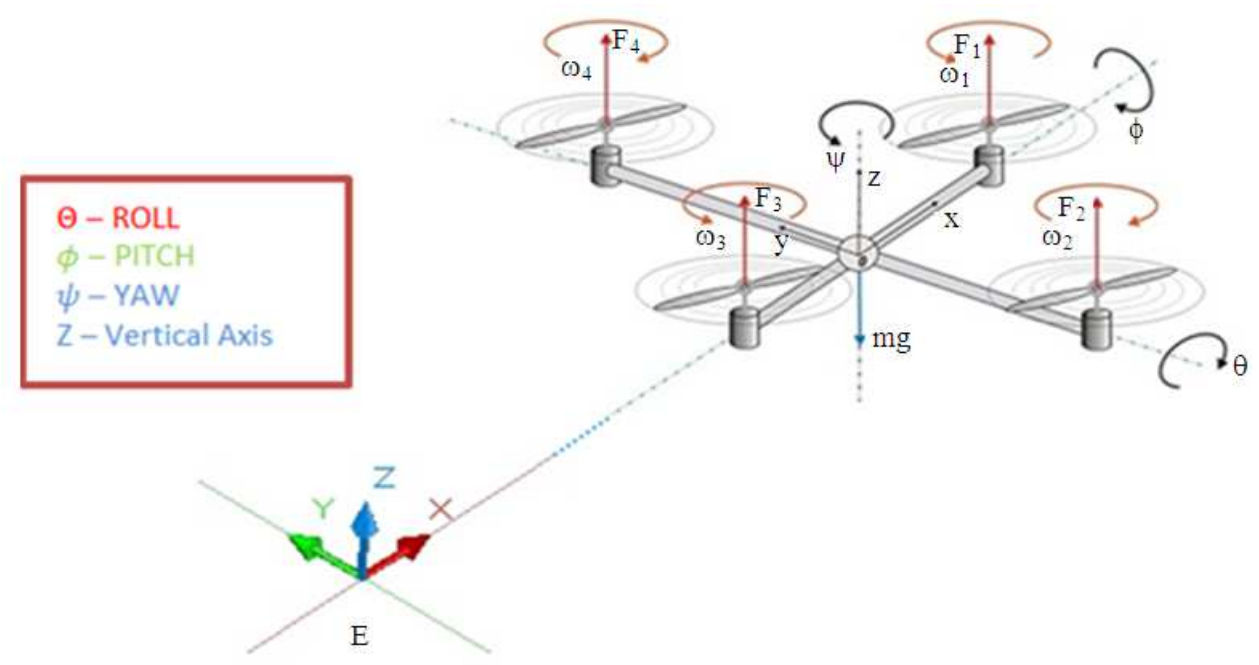

Fig. 2. Quad-rotor Body and Earth Inertial Frame

The Quad-rotor system is composed of linear equations with respect to E-frame and angular equations with respect to B-frame. Therefore the quad-rotor generalized velocity vector can be expressed in the new frame called $\mathrm{H}$-frame shown in Equation 7:

$$
\zeta=\left[\begin{array}{ll}
\dot{\Gamma}^{\mathrm{E}} & \omega^{\mathrm{B}}
\end{array}\right]=\left[\begin{array}{llllll}
\dot{\mathrm{X}} & \dot{\mathrm{Y}} & \dot{\mathrm{Z}} & \phi & \theta & \psi
\end{array}\right]^{\mathrm{T}}
$$

By contributing the effect of gyroscope, gravitational vector and quad-rotor movement vector (Becker et al., 2012) we can calculate the quad-rotor system dynamic as define in Equation 8:

$$
\begin{aligned}
& \ddot{X}=(\sin \psi \sin \phi+\cos \psi \sin \theta \cos \phi) \frac{\mathrm{U}_{1}}{\mathrm{~m}} \\
& \ddot{Y}=(-\cos \psi \sin \phi+\sin \psi \sin \theta \cos \phi) \frac{\mathrm{U}_{1}}{\mathrm{~m}} \\
& \ddot{Z}=-\mathrm{g}+(\cos \theta \cos \phi) \frac{\mathrm{U}_{1}}{\mathrm{~m}} \\
& \ddot{\phi}=\frac{\mathrm{I}_{\mathrm{YY}}-\mathrm{I}_{\mathrm{ZZ}}}{\mathrm{I}_{\mathrm{XX}}} \theta \psi-\frac{\mathrm{J}_{\mathrm{TP}}}{\mathrm{I}_{\mathrm{XX}}} \theta \omega+\frac{\mathrm{U}_{2}}{\mathrm{I}_{\mathrm{XX}}} \\
& \ddot{\theta}=\frac{\mathrm{I}_{\mathrm{ZZ}}-\mathrm{I}_{\mathrm{XX}}}{\mathrm{I}_{\mathrm{YY}}} \theta \psi-\frac{\mathrm{J}_{\mathrm{TP}}}{\mathrm{I}_{\mathrm{YY}}} \theta \omega+\frac{\mathrm{U}_{3}}{\mathrm{I}_{\mathrm{YY}}} \\
& \ddot{\psi}=\frac{\mathrm{I}_{\mathrm{XX}}-\mathrm{I}_{\mathrm{YY}}}{\mathrm{I}_{\mathrm{ZZ}}} \theta \psi-\frac{\mathrm{U}_{4}}{\mathrm{I}_{\mathrm{ZZ}}}
\end{aligned}
$$

where, U1, U2, U3 and U4 are the movement vector components define in Equation (9). Their relation with the propellers' speeds comes from aerodynamic calculus (Lee et al., 2011):

$$
\left\{\begin{array}{l}
\mathrm{U}_{1}=\mathrm{b}\left(\omega_{1}{ }^{2}+\omega_{2}{ }^{2}+\omega_{3}{ }^{2}+\omega_{4}{ }^{2}\right) \\
\mathrm{U}_{2}=\mathrm{lb}\left(-\omega_{2}{ }^{2}+\omega_{4}{ }^{2}\right) \\
\mathrm{U}_{3}=\mathrm{lb}\left(\omega_{1}{ }^{2}+\omega_{3}{ }^{2}\right) \\
\mathrm{U}_{4}=\mathrm{d}\left(-\omega_{1}{ }^{2}+\omega_{2}{ }^{2}-\omega_{3}{ }^{2}+\omega_{4}{ }^{2}\right)
\end{array}\right.
$$

where, ' 1 ', $b$ and $d$ are the arm length, thrust constant and drag constant respectively.

\subsection{Proposed Controller Design}

In this study PID controller technique is proposed for appropriate altitude and attitude controlling of quad-rotor under the disturbance condition. Besides that EKF is also proposed to filter out the noises caused by sensor and system.

Figure 3 shows the overall block diagram of Proposed Control Algorithm and the plant dynamics are presented in Equation (10) for altitude and attitude controlling of quad-rotor. For smooth controlling of quad-rotor Altitude, z-axis equation will be used and for attitude controlling all three angles which are roll, pitch and yaw will be used in controller designing:

$$
\begin{aligned}
& \ddot{Z}=-g+(\cos \theta \cos \phi) \frac{\mathrm{U}_{1}}{\mathrm{~m}} \\
& \ddot{\phi}=\frac{\mathrm{I}_{\mathrm{YY}} \mathrm{I}_{\mathrm{ZZ}}}{\mathrm{I}_{\mathrm{XX}}} \theta \psi-\frac{\mathrm{J}_{\mathrm{TP}}}{1_{\mathrm{XX}}} \theta \Omega+1 \frac{\mathrm{U}_{2}}{1_{\mathrm{XX}}} \\
& \ddot{\theta}=\frac{1_{\mathrm{ZZ}} 1_{\mathrm{XX}}}{1_{\mathrm{YY}}} \theta \psi-\frac{\mathrm{J}_{\mathrm{TP}}}{1_{\mathrm{YY}}} \theta \Omega+1 \frac{\mathrm{U}_{3}}{\mathrm{I}_{\mathrm{YY}}} \\
& \ddot{\psi}=\frac{1_{\mathrm{XX}} 1_{\mathrm{YY}}}{1_{\mathrm{ZZ}}} \theta \psi-1 \frac{\mathrm{U}_{4}}{1_{\mathrm{ZZ}}}
\end{aligned}
$$


The main objective of this research is to design Controller which makes quad-rotor stable under the circumstances of disturbance. In order to deal with this major issue an appropriate PID Controller is presented in this study for making the system stabilize under the disturbance condition. The PID control is tuned by auto-tuning method and its range between 0 to1 for all parameters.

The other common problem in quad-rotor is that basically during sensor data is distorted due to noise; to overcome this problem hence Extended Kalman Filter is introduced.

\subsection{EKF for Noise Rejection}

Quad-rotor UAV are non-linear systems, so for the estimation of the true system output and filter out the noises Extended Kalman Filter (EKF) technique can be to used. EKF lies on the principles of linearization of the current estimation error mean and covariance (Zhang et al., 2011).

Considering a standard state space model of a nonlinear system:

$$
\begin{aligned}
& \mathrm{X}_{\mathrm{k}+1}=\mathrm{f}\left(\mathrm{x}_{\mathrm{k}}, \mathrm{u}_{\mathrm{k}}\right)+\mathrm{w}_{\mathrm{k}} \\
& \overline{\mathrm{y}}_{\mathrm{k}}=\mathrm{h}\left(\mathrm{x}_{\mathrm{k}}\right)+\mathrm{v}_{\mathrm{k}}
\end{aligned}
$$

where, ' $\mathrm{x}_{\mathrm{k}}$ ' is a state vector in Equation (11), ' $\bar{y}_{\mathrm{k}}$ ' is a measured process output in Equation (12), ' $\mathrm{w}_{\mathrm{k}}$ ' and ' $\mathrm{v}_{\mathrm{k}}$ ' are the process and measurement noises respectively. $\mathrm{F}($.$) and \mathrm{h}($.) are generic nonlinear functions.

The extended Kalman filter is used to estimate unmeasured states and the actual process outputs.

Likewise the standard kalman filter, the EKF also uses two step prediction and correction algorithm. The time update equations of EKF are:

$$
\begin{aligned}
& \hat{\mathrm{x}}_{\mathrm{k}+1}=\mathrm{f}\left(\hat{\mathrm{x}}_{\mathrm{k}}, \mathrm{u}_{\mathrm{k}}\right) \\
& \mathrm{P}_{\mathrm{k}+1}=\mathrm{A}_{\mathrm{k}} \mathrm{P}_{\mathrm{k}} \mathrm{A}_{\mathrm{k}}{ }^{\mathrm{T}}+\mathrm{Q}
\end{aligned}
$$

where, ' $\hat{\mathrm{x}}_{\mathrm{k}+1}$ ' is prior state estimate in Equation (13). The time update equations project the state and covariance estimate ' $\mathrm{P}_{\mathrm{k}+1}$ ' from previous time step ' $\mathrm{k}$ ' to the current time step ' $\mathrm{k}+1$ ' Equation (14) (Zhang et al., 2011).

The measurement update equations of EKF are Equation (15-17):

$$
\begin{aligned}
& \mathrm{K}_{\mathrm{k}}=\mathrm{P}_{\mathrm{k}} \mathrm{C}_{\mathrm{k}}^{\mathrm{T}}\left(\mathrm{C}_{\mathrm{k}} \mathrm{P}_{\mathrm{k}} \mathrm{C}_{\mathrm{k}}^{\mathrm{T}}+\mathrm{R}\right)^{-1} \\
& \hat{\mathrm{x}}_{\mathrm{k}+1}=\mathrm{f}\left(\hat{\mathrm{x}}_{\mathrm{k}}, \mathrm{u}_{\mathrm{k}}\right)+\mathrm{K}_{\mathrm{k}}\left[\overline{\mathrm{y}}_{\mathrm{k}}-\mathrm{h}\left(\hat{\mathrm{x}}_{\mathrm{k}}\right)\right]
\end{aligned}
$$

$\mathrm{P}_{\mathrm{k}+1}=\mathrm{A}_{\mathrm{k}}\left(1-\mathrm{K}_{\mathrm{k}} \mathrm{C}_{\mathrm{k}}\right) \mathrm{P}_{\mathrm{k}}$

where, ' $\mathrm{K}$ ' is the correction Kalman gain vector and ' $\mathrm{A}_{\mathrm{k}}$ ' and ' $\mathrm{C}_{\mathrm{k}}$ ' cannot be used directly. With this type of limitation either Taylor series is applied or Jacobian is used. The Jacobians are defined as Equation (18 and 19):

$$
\begin{aligned}
& A_{k}=f^{\prime}\left(\hat{x}_{k}, u_{k}\right) \\
& C_{k}=h^{\prime}\left(\hat{x}_{k}\right)
\end{aligned}
$$

where, $f($.$) can be evaluated as in the Equation 20:$

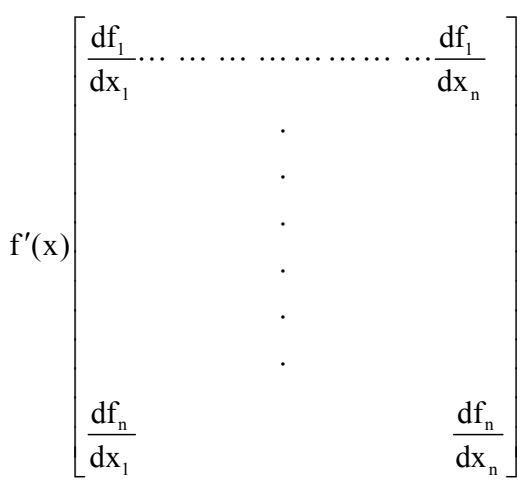

\subsection{Attitude Stabilization Controller}

The EKF filtered feedback signal combined with reference signal and produces error signal which goes to PID control block as shown in (Fig. 3). For Quad-rotor attitude controlling only orientation angles i.e., pith, roll and yaw are controlled. The Block diagram of PID controller based Attitude controller for quad-rotor is illustrated in (Fig. 4). The quad-rotor dynamics must be simplified while hovering. There are some of the terms that can be neglected which are gyroscopic torque and Coriolis-centripetal as mentioned in (Ryll et al., 2012).

After neglecting the terms in Equation (10), the equation becomes simpler as Equation (21):

$$
\left[\begin{array}{c}
\ddot{\phi} \\
\ddot{\theta} \\
\ddot{\psi}
\end{array}\right]=\left[\begin{array}{l}
\frac{\mathrm{L}}{\mathrm{I}_{\mathrm{xx}}} \mathrm{u}_{2} \\
\frac{\mathrm{L}}{\mathrm{I}_{\mathrm{yy}}} \mathrm{u}_{3} \\
\frac{1}{\mathrm{I}_{\mathrm{zz}}} \mathrm{u}_{4}
\end{array}\right]
$$

By applying Laplace Transform on Equation (21), the transfer function of quad-rotor plant's attitude which is roll, pitch and yaw obtained separately as Equation 22: 


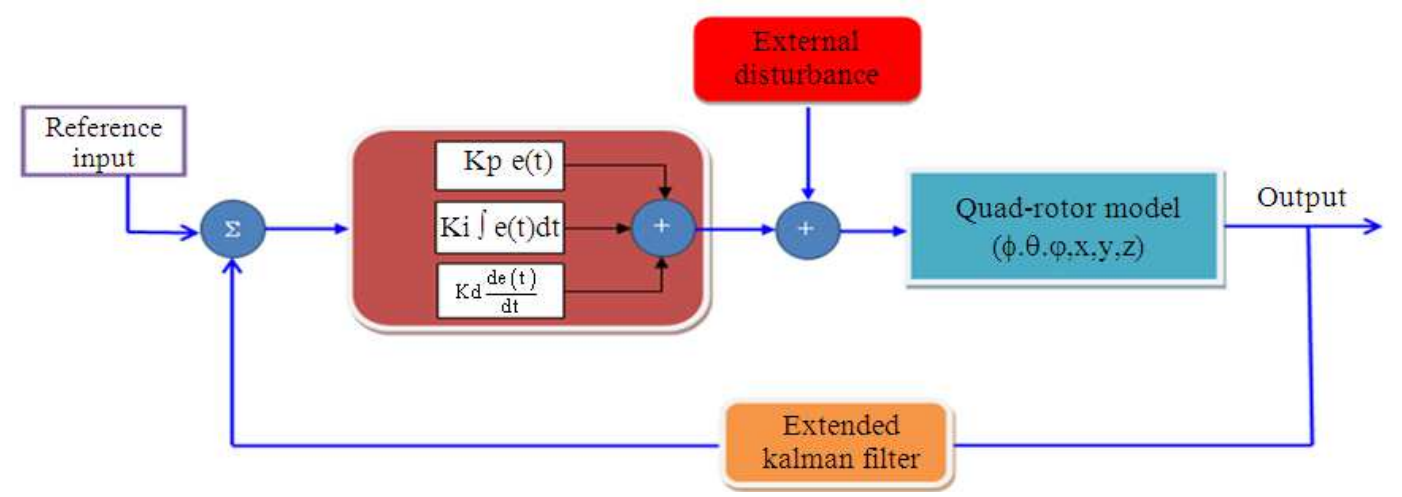

Fig. 3. Proposed control system

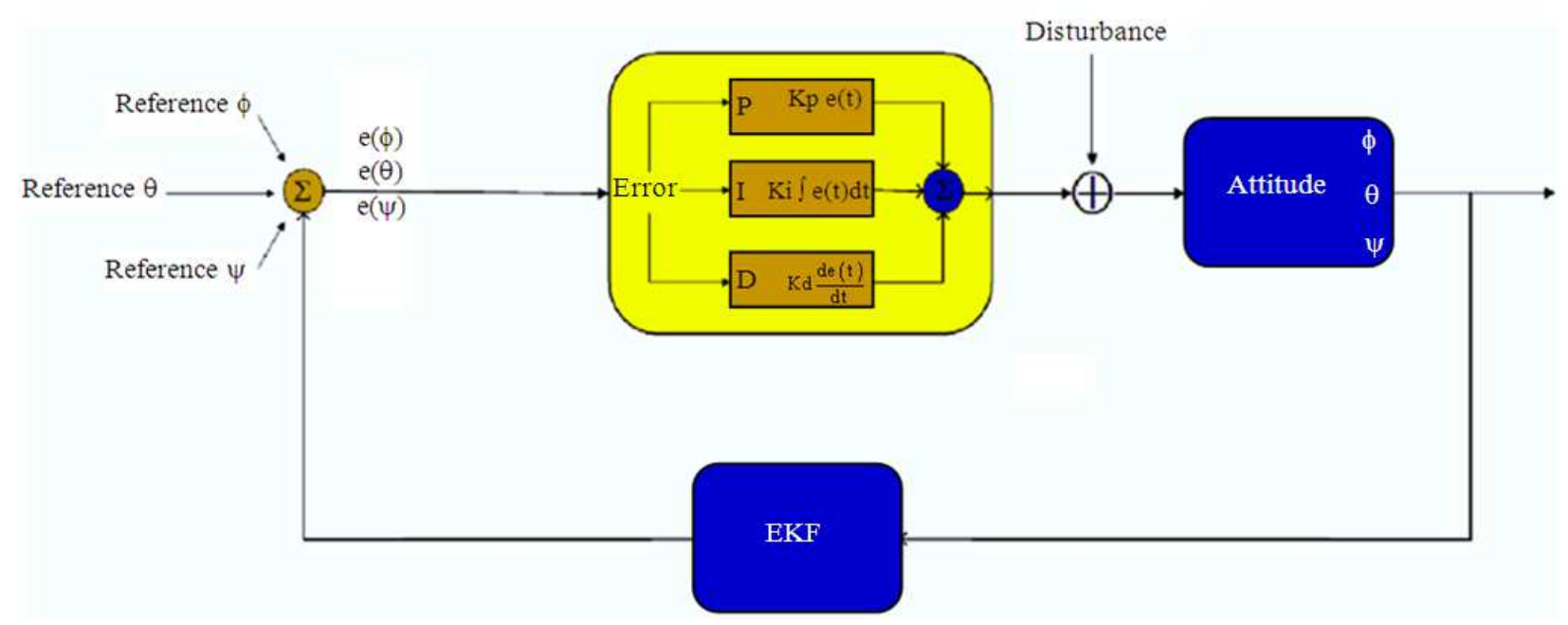

Fig. 4. Block diagram of attitude controller

$$
\begin{aligned}
& \frac{\phi(s)}{\mathrm{u}_{2}(\mathrm{~s})}=\frac{\mathrm{L}}{1_{\mathrm{Xx}} \mathrm{s}^{2}} \\
& \frac{\theta(\mathrm{s})}{\mathrm{u}_{3}(\mathrm{~s})}=\frac{1}{\mathrm{I}_{\mathrm{yys}}{ }^{2}} \\
& \frac{\psi(\mathrm{s})}{\mathrm{u}_{4}(\mathrm{~s})}=\frac{1}{\mathrm{I}_{\mathrm{zzs}^{2}}}
\end{aligned}
$$

So for its controller designing, the error signals $\mathrm{e}_{\phi}, \mathrm{e}_{\theta}$, $\mathrm{e}_{\psi}$ will be:

$$
\begin{aligned}
& \mathrm{e}_{\phi}=\phi_{\text {ref }}-\phi \\
& \mathrm{e}_{\theta}=\theta_{\text {ref }}-\theta \\
& \mathrm{e}_{\psi}=\psi_{\text {ref }}-\psi
\end{aligned}
$$

For Roll angle controlling, following equation will be take in account:

$$
\phi(\mathrm{s})=\frac{1 \mathrm{U}_{2}}{\mathrm{I}_{\mathrm{XX}} \mathrm{S}^{2}}
$$

After evaluating roll angle with rotor dynamics given in Equation 23 the above equation becomes Equation (24):

$$
\phi(s)=\frac{\left(0.936^{2}\right) 1}{1_{\mathrm{XX}} \mathrm{s}^{2}(1.78 \mathrm{~S}+1)^{2}} \mathrm{U}
$$

where, $\left(\frac{\left(0.936^{2}\right) 1}{\mathrm{I}_{\mathrm{xx}}}\right)$ is constant and can be taken equal

to $\mathrm{K}_{\mathrm{a}}$. The difference between rotor is given by $\mathrm{U}$ Equation (25): 
$\phi(s)=\frac{\mathrm{K}_{\mathrm{a}}}{\mathrm{S}^{2}(1.78 \mathrm{~S}+1)^{2}} \mathrm{U}$

$$
\phi(\mathrm{s})=\frac{\mathrm{K}_{\mathrm{a}}}{3.16 \mathrm{~S}^{4}+3.5 \mathrm{~S}^{3}+\mathrm{S}^{2}} \mathrm{U}
$$

The PID equation is Equation (26):

$$
\mathrm{PID}=\mathrm{K}_{\mathrm{p}} \mathrm{e}(\mathrm{s})+\frac{\mathrm{K}_{\mathrm{i}}}{\mathrm{S}} \mathrm{e}(\mathrm{s})+\mathrm{SK}_{\mathrm{d}} \mathrm{e}(\mathrm{s})
$$

After applying PID to the system the equation for attitude stabilization of roll becomes Equation (27):

$$
\begin{aligned}
& \phi=\mathrm{e}(\mathrm{s}) \\
& {\left[\frac{\mathrm{S}^{2} \mathrm{~K}_{\mathrm{d}} \mathrm{K}_{\mathrm{a}}+\mathrm{SK}_{\mathrm{p}} \mathrm{K}_{\mathrm{a}}+\mathrm{K}_{\mathrm{i}} \mathrm{K}_{\mathrm{a}}}{3.16 \mathrm{~S}^{5}+3.5 \mathrm{~S}^{4}+\mathrm{S}^{3}+\mathrm{S}^{2} \mathrm{~K}_{\mathrm{d}} \mathrm{K}_{\mathrm{a}}+\mathrm{SK}_{\mathrm{p}} \mathrm{K}_{\mathrm{a}}+\mathrm{K}_{\mathrm{i}} \mathrm{K}_{\mathrm{a}}}\right] \mathrm{U}}
\end{aligned}
$$

Similarly for other angles of attitude (i.e., pitch and yaw), can obtain by same above mentioned proposed method.

\subsection{For Altitude Stabilization}

For achieving stabilized altitude of Quad-rotor we have to work on quad-rotor $Z$ axis and all axes remaining constant. So we select Only $\mathrm{Z}$ axis equation form Equation (10), as show in following:

$$
\ddot{z}=g-(\cos \varnothing \cos \theta) \frac{U_{1}}{m}
$$

In above equation $\mathrm{g}=9.86$ and $\mathrm{m}=9.68$, where with respect of time $\phi$ and $\theta$ must be considered as 0 for hovering condition, change their values and giving a constant value at a particular time $\ddot{z}=9.86-\frac{U_{1}}{m}$. After evaluating rotor dynamics in plant equation will become:

$$
\ddot{z}=9.86-\left(\frac{0.936}{0.178 \mathrm{~S}+1}\right)^{2}\left(\frac{1}{0.65}\right) \times 4
$$

Using laplace Transform, system will become Equation (28):

$$
Z(s)=\frac{0.3 S^{2}+3.5 S+4.46}{0.03 S^{4}+0.35 S^{3}+S^{2}}
$$

So the error signals E for PID control is:

$$
\mathrm{e}_{\mathrm{z}}=\mathrm{Z}_{\text {ref }}-\mathrm{Z}
$$

and PID controller will become Equation (29):

$$
\mathrm{U}(\mathrm{s})=\mathrm{K}_{\mathrm{p}} \mathrm{e}(\mathrm{s})+\frac{\mathrm{K}_{\mathrm{i}}}{\mathrm{S}} \mathrm{e}(\mathrm{s})+\mathrm{K}_{\mathrm{d}} \mathrm{Se}(\mathrm{s})
$$

$\mathrm{K}_{\mathrm{p}}, \mathrm{K}_{\mathrm{i}}$ and $\mathrm{K}_{\mathrm{d}}$ can be selected by Auto tuning method:

$$
Z(S)=\left(\frac{0.3 S^{2}+3.5 S+4.46}{0.03 S^{4}+0.35 S^{3}+S^{2}}\right)\left(K_{p} e(s)+\frac{K_{i}}{S} e(s)+S_{d} e(s)\right)
$$

Let:

$$
\begin{aligned}
& \mathrm{K}_{1}=0.3 \mathrm{~K}_{\mathrm{d}}=1 \\
& \mathrm{~K}_{2}=\left(3.5 \mathrm{~K}_{\mathrm{d}}+0.3 \mathrm{~K}_{\mathrm{P}}\right)=(2 \mathrm{~b}+2 \mathrm{a}) \\
& \mathrm{K}_{3}=\left(0.3 \mathrm{~K}_{\mathrm{p}}+0.3 \mathrm{~K}_{\mathrm{i}}+4.46 \mathrm{~K}_{\mathrm{d}}\right)=\left(\mathrm{b}^{2}+4 \mathrm{ab}+\mathrm{a}^{2}\right) \\
& \mathrm{K}_{4}=\left(0.3 \mathrm{~K}_{\mathrm{i}}+4.46 \mathrm{~K}_{\mathrm{p}}\right)=\left(2 \mathrm{ab}^{2}+2 \mathrm{a}^{2} \mathrm{~b}\right) \\
& \mathrm{K}_{5}=4.46 \mathrm{~K}_{\mathrm{i}}=\mathrm{a}^{2} \mathrm{~b}^{2}
\end{aligned}
$$

Therefore close loop transfer function for the complete system will become:

$$
\begin{aligned}
& \frac{Y(s)}{R(s)}= \\
& \frac{K_{1} S^{4}+K_{2} S^{3}+K_{3} S^{2}+K_{4} S+K_{5}}{S^{5}+\left(K_{d}+1\right) S^{4}+\left(K_{p}+K_{d}+1\right) S^{3}+K_{3} S^{2}+K_{4} S+K_{5}} e(s)
\end{aligned}
$$

\subsection{Controller Stability Analysis}

Illustrating the parameters of Equation 30 and simplify it for proving stability through lyapunov theorem.

Taking it can be considered as Equation (31):

$$
\begin{aligned}
& =>(S+a)^{2}(S+b)^{2}=0 \\
& =>\left(S^{2}+2 a s+a^{2}\right)\left(S^{2}+2 b s+b^{2}\right)=0
\end{aligned}
$$

Solving Equation 30 in stipulations of above equation for proving stability, we get:

$$
\begin{aligned}
& \left(\mathrm{S}^{2}+2 \mathrm{aS}+\mathrm{a}^{2}\right)=0 \\
& \mathrm{~K}_{\mathrm{A}} \mathrm{S}^{2}+\mathrm{K}_{\mathrm{B}} \mathrm{S}+\mathrm{K}_{\mathrm{C}}=0
\end{aligned}
$$

Converting above equation to time domain:

$$
\mathrm{K}_{\mathrm{A}} \ddot{\mathrm{e}}+\dot{\mathrm{e}} \mathrm{K}_{\mathrm{B}}+\mathrm{eK}_{\mathrm{C}}=0
$$


Solving Equation (32) as state space representation it can be written as Equation (33):

$$
\frac{\mathrm{d}}{\mathrm{dt}}\left[\begin{array}{c}
\mathrm{e} \\
\dot{\mathrm{e}}
\end{array}\right]=\left[-\left(\frac{\mathrm{K}_{\mathrm{C}}}{\mathrm{K}_{\mathrm{A}}}\right) \mathrm{e}-\left(\frac{\mathrm{K}_{\mathrm{B}}}{\mathrm{K}_{\mathrm{A}}}\right) \dot{\mathrm{e}}\right]
$$

Define $\mathrm{x}=(\mathrm{e}, \dot{\mathrm{e}})$ as the state of the system. Since this system is a linear system, we can determine stability by examining the poles of the system. Wang et al. (2011), the Jacobian matrix for the system is Equation (34):

$$
A=\left[\begin{array}{cc}
0 & 1 \\
-\left(\frac{K_{C}}{K_{A}}\right) & -\left(\frac{K_{B}}{K_{A}}\right)
\end{array}\right]
$$

which has a characteristic equation:

$$
\lambda^{2}+\frac{\mathrm{K}_{\mathrm{B}}}{\mathrm{K}_{\mathrm{A}}} \lambda+\frac{\mathrm{K}_{\mathrm{C}}}{\mathrm{K}_{\mathrm{A}}}=0
$$

The solutions of the characteristic Equation (35) are:

$$
\lambda \frac{-\left(\mathrm{K}_{\mathrm{B}}\right) \pm \sqrt{\left(\mathrm{K}_{\mathrm{B}}\right)^{2}-4\left(\mathrm{~K}_{\mathrm{C}}\right)\left(\mathrm{K}_{\mathrm{A}}\right)}}{2\left(\mathrm{~K}_{\mathrm{A}}\right)}
$$

Which always have negative real parts and hence the system is (globally) exponentially stable.

We now try to apply Lyapunov's direct method to determine exponential stability. The "obvious" Lyapunov function to use in this context is the energy of the system Equation (36):

$$
\mathrm{V}(\mathrm{x}, \mathrm{t})=\frac{1}{2} \mathrm{~K}_{\mathrm{A}} \dot{\mathrm{e}}^{2}+\frac{1}{2} \mathrm{~K}_{\mathrm{C}} \mathrm{e}^{2}
$$

Taking derivative of V Equation (37):

$$
\dot{\mathrm{V}}=\mathrm{K}_{\mathrm{A}} \ddot{\mathrm{e}}+\mathrm{K}_{\mathrm{C}} \mathrm{e} \dot{\mathrm{e}}=\mathrm{K}_{\mathrm{B}} \dot{\mathrm{e}}^{2}
$$

The function $-\dot{V}$ is quadratic but not locally positive definite because it depends upon e., so for that here slightly skew being made so that the flow of system crosses the level surface transversely.

$\in$ Introduces here showing small positive constant and shows that $\mathrm{V}$ is still positive definite Equation 38:

$$
\mathrm{V}(\mathrm{x}, \mathrm{t})=\frac{1}{2} \dot{\mathrm{e}} \mathrm{K}_{\mathrm{A}} \dot{\mathrm{e}}+\frac{1}{2} \mathrm{eK}_{\mathrm{C}} \mathrm{e}+\in \dot{\mathrm{e}} \mathrm{K}_{\mathrm{A}} \mathrm{e}
$$

The derivative of Lyapunov will become:

$$
\dot{V}=\dot{e} K_{A} \ddot{e}+e K_{C} \dot{e}+\in K_{A} \dot{e}^{2}+\in \mathrm{eK}_{A} \ddot{e}
$$

Solving Equation 39 now Equation 40:

$$
\dot{\mathrm{V}}=\left(-\mathrm{K}_{\mathrm{B}}+\in \mathrm{K}_{\mathrm{A}}\right) \dot{\mathrm{e}}^{2}+\in\left(-\mathrm{K}_{\mathrm{C}} \mathrm{e}^{2}-\mathrm{K}_{\mathrm{B}} \mathrm{e} \dot{\mathrm{e}}\right)
$$

The function $\dot{\mathrm{V}}$ can be made negative definite for $\epsilon$ chosen sufficiently small and hence we can conclude that system satisfies exponential stability (Wang et al., 2011).

From Equation 32, 41 and 42:

$K_{A} \ddot{e}+K_{C} e=u(t), u=K_{B} \dot{e}$

$\mathrm{K}_{\mathrm{A}}=\mathrm{K}_{\mathrm{A}}{ }^{\mathrm{T}}>0, \mathrm{~K}_{\mathrm{C}}=-\mathrm{K}_{\mathrm{C}}{ }^{\mathrm{T}}>0, \mathrm{~K}_{\mathrm{B}}=\mathrm{K}_{\mathrm{B}}{ }^{\mathrm{T}}>0$

Letting $\mathrm{x}_{1}=\mathrm{e}, \mathrm{x}_{2}=\dot{\mathrm{e}}$, we have

$\dot{\mathrm{x}}_{1}=\mathrm{x}_{2} \dot{\mathrm{x}}_{2}=-\mathrm{K}_{\mathrm{A}}^{-1} \mathrm{~K}_{\mathrm{C}} \mathrm{x}_{1}-\mathrm{K}_{\mathrm{A}}^{-1} \mathrm{~K}_{\mathrm{B}} \mathrm{x}_{2}$

Let Equation 43:

$\mathrm{V}=\frac{2}{\mathrm{Z}} \dot{\mathrm{e}}^{\mathrm{T}} \mathrm{K}_{\mathrm{A}} \dot{\mathrm{e}} \dot{+} \frac{2}{\mathrm{Z}} \mathrm{e}^{\mathrm{T}} \mathrm{K}_{\mathrm{C}} \mathrm{e}=\frac{1}{2}\left[\mathrm{x}_{2}{ }^{\mathrm{T}} \mathrm{x}_{2}{ }^{\mathrm{T}}\right]$

$\left[\begin{array}{cc}\mathrm{K}_{\mathrm{C}} & 0 \\ 0 & \mathrm{~K}_{\mathrm{A}}\end{array}\right]\left[\begin{array}{l}\mathrm{x}_{1} \\ \mathrm{x}_{2}\end{array}\right]>(\mathrm{x} \neq 0)$

This is a radially unbounded pdf. Then Equation 44 :

$$
\begin{aligned}
& \dot{\mathrm{V}}=\dot{\mathrm{e}}^{\mathrm{T}}\left(\mathrm{K}_{\mathrm{A}} \ddot{\mathrm{e}}+\mathrm{K}_{\mathrm{C}} \mathrm{e}\right)=-\dot{\mathrm{e}}^{\mathrm{T}} \mathrm{K}_{\mathrm{B}} \dot{\mathrm{e}}= \\
& -\left[\begin{array}{ll}
\mathrm{x}_{1}{ }^{\mathrm{T}} & \mathrm{x}_{2}{ }^{\mathrm{T}}
\end{array}\right]\left[\begin{array}{cc}
0 & 0 \\
0 & \mathrm{~K}_{\mathrm{B}}
\end{array}\right]\left[\begin{array}{l}
\mathrm{x}_{1} \\
\mathrm{x}_{2}
\end{array}\right] \leq 0
\end{aligned}
$$

Hence, $x=0$ is a stable equilibrium. It is in fact globally asymptotically stable.

\section{RESULTS AND DISCUSSION}

For simulation quad-rotor system parameters are chosen as given in (Table 1). The simulation result presented exposes the effectiveness of controller to stabilize the quad-rotor attitude and altitude under disturbance conditions. The closed loop system behaviors are analyzed while hovering in the presence of unknown disturbance injected on attitude of quad-rotor. 
M. Hassan Tanveer et al. / American Journal of Applied Sciences 10 (8): 819-831, 2013

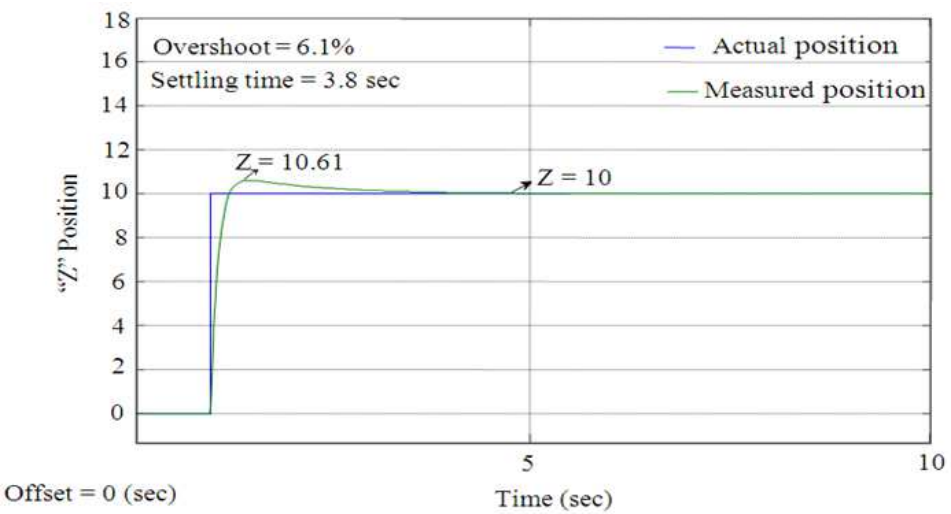

Fig. 5. Altitude controller
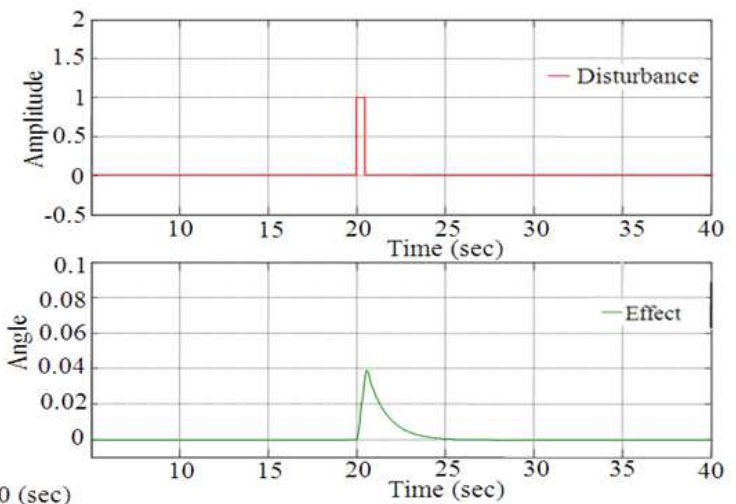

Offset $=0(\mathrm{sec})$

Fig. 6. Disturbance and its effect on roll angle

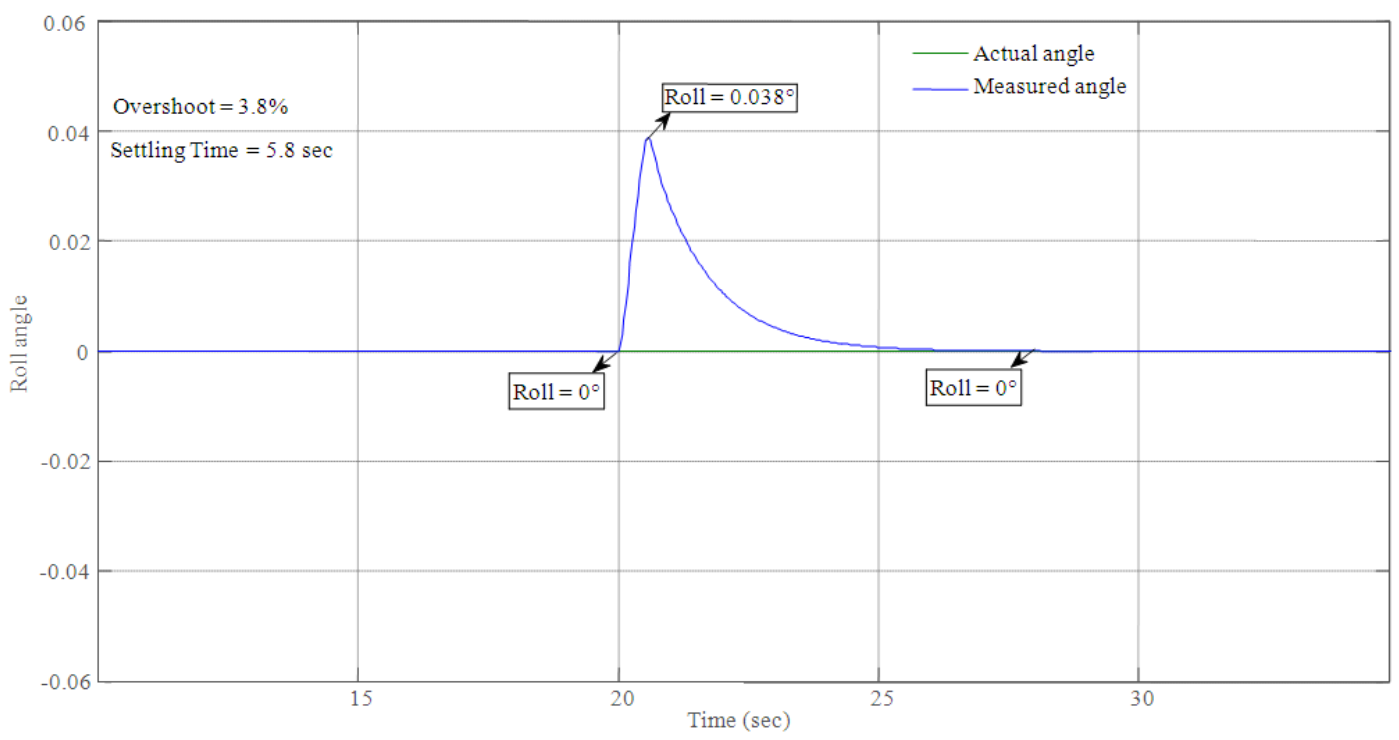

Offset $=0(\mathrm{sec})$

Fig. 7. Attitude Control (Roll angle) 
M. Hassan Tanveer et al. / American Journal of Applied Sciences 10 (8): 819-831, 2013
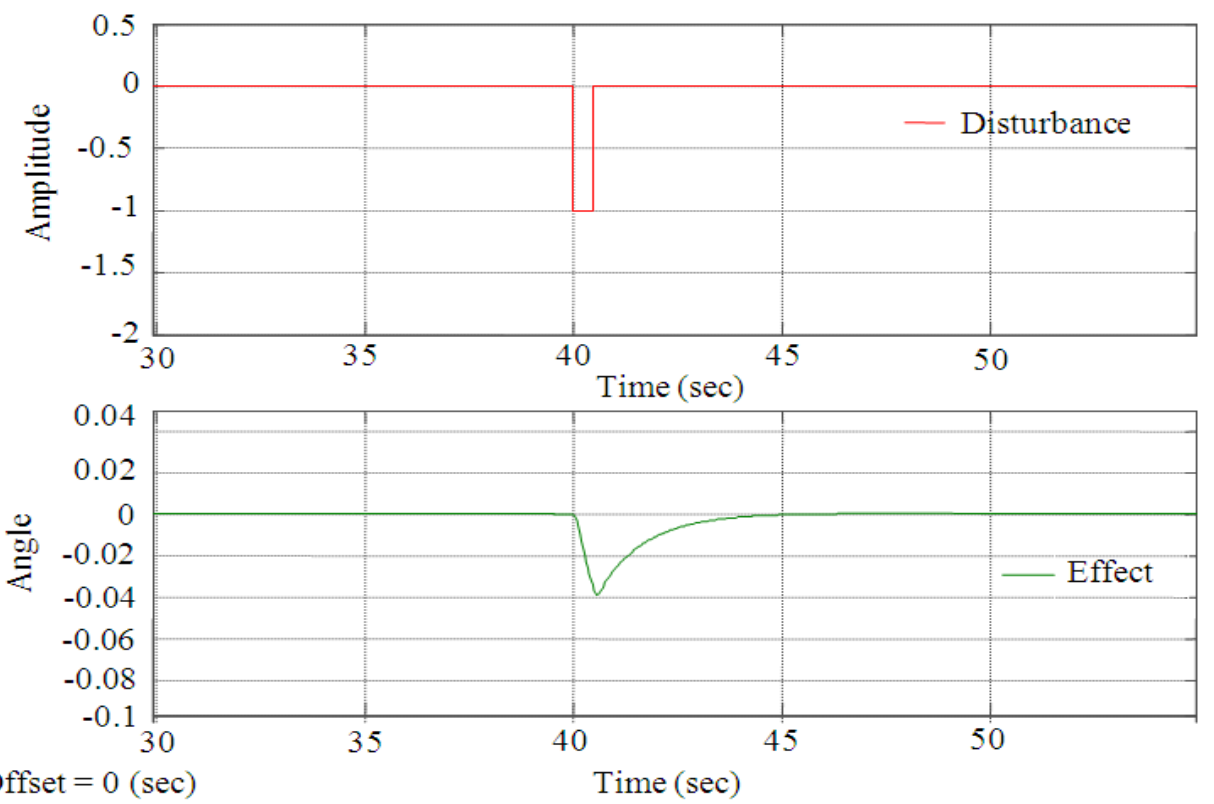

Fig. 8. Disturbance and its effect on pitch angle

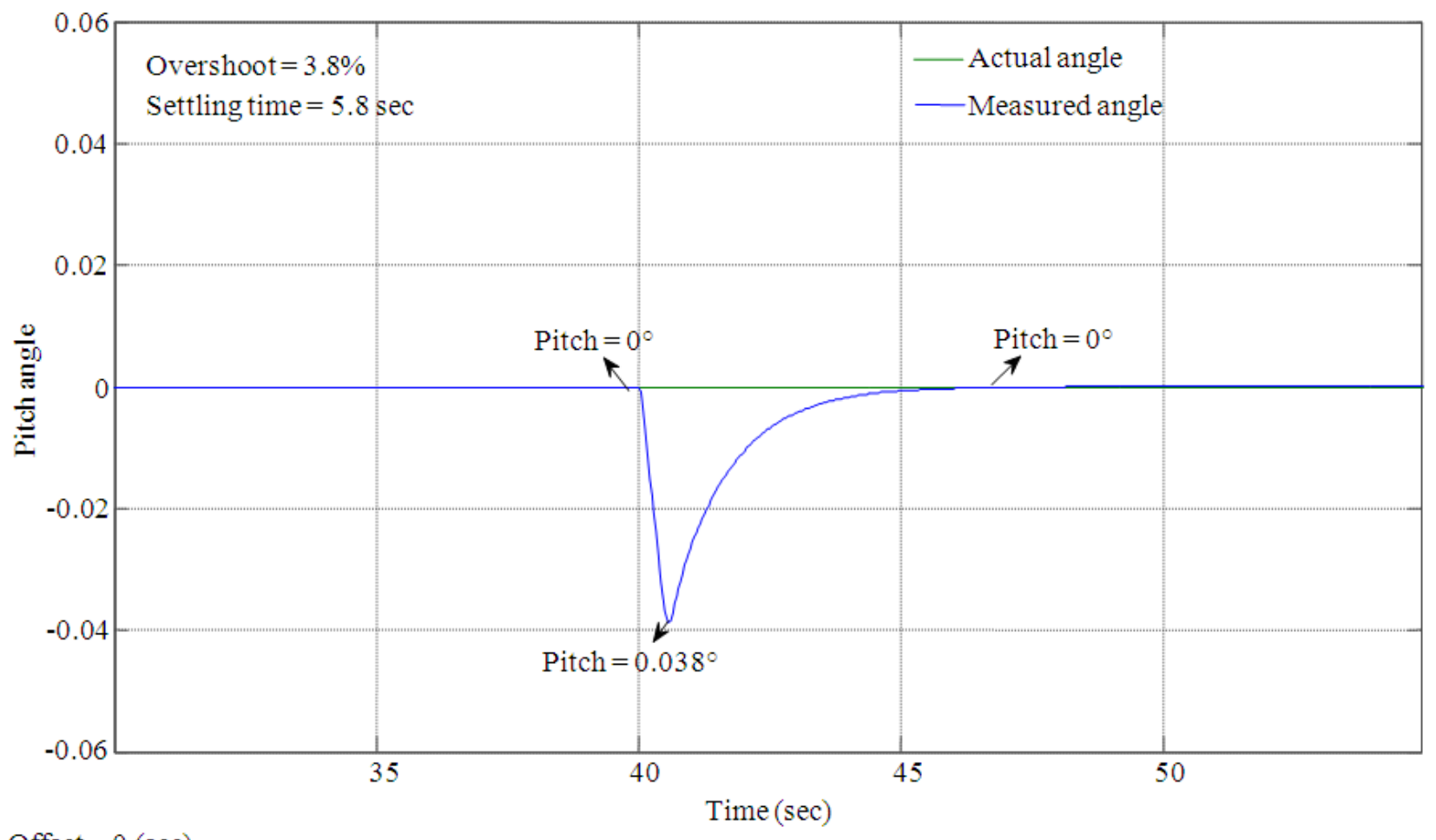

Offset $=0(\mathrm{sec})$

Fig. 9. Attitude control (pitch angle) 
M. Hassan Tanveer et al. / American Journal of Applied Sciences 10 (8): 819-831, 2013
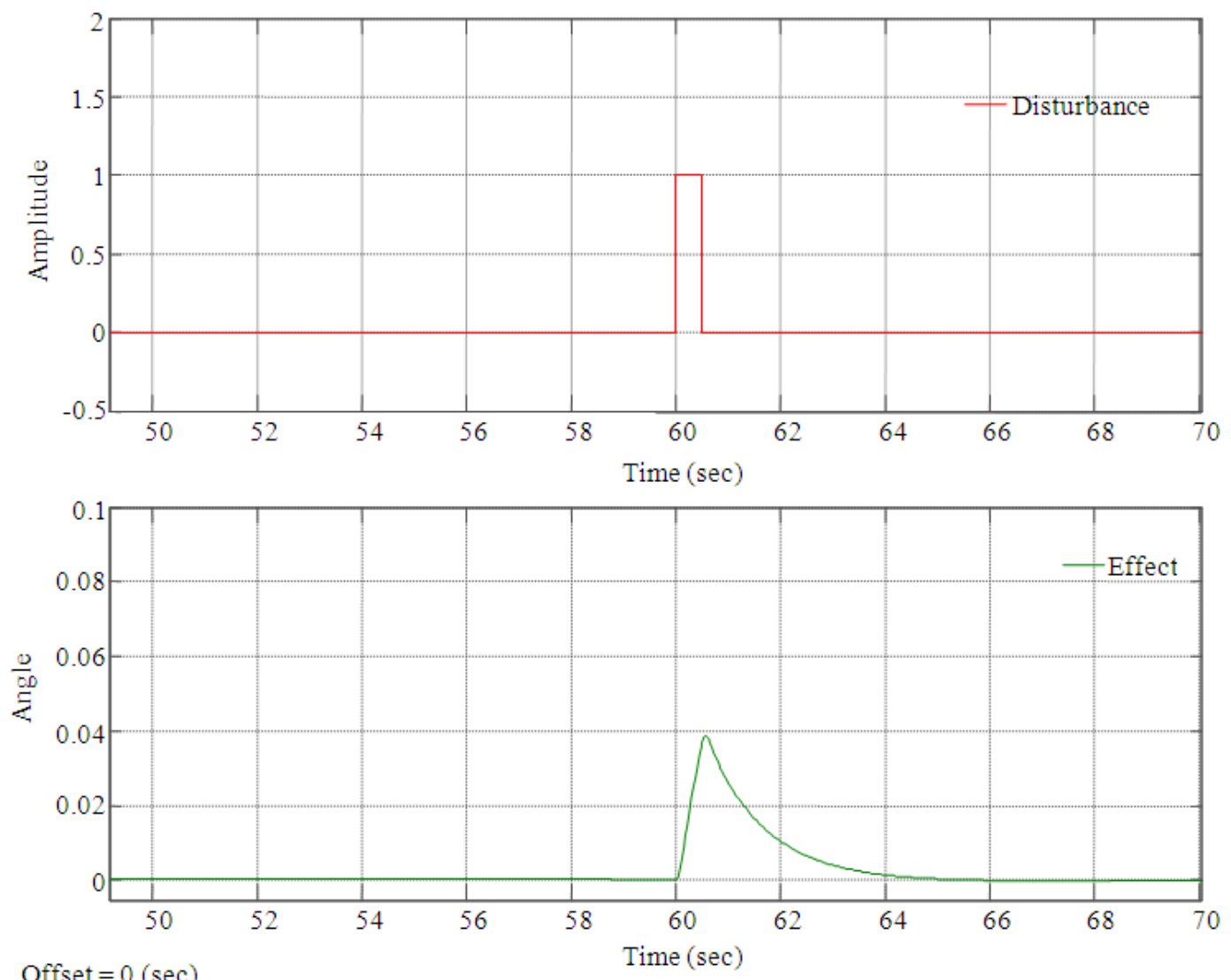

Offset $=0(\mathrm{sec})$

Fig. 10. Disturbance and its effect on yaw angle

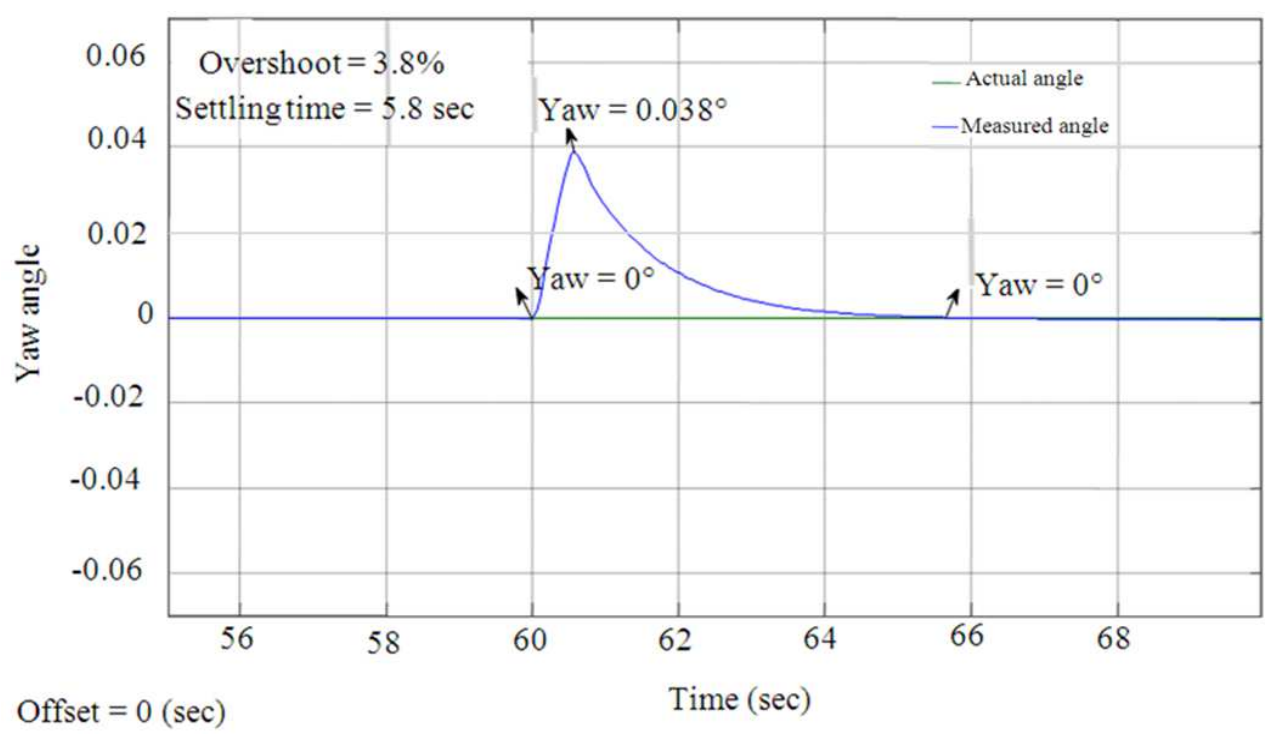

Fig. 11. Attitude control (Yaw angle) 
M. Hassan Tanveer et al. / American Journal of Applied Sciences 10 (8): 819-831, 2013

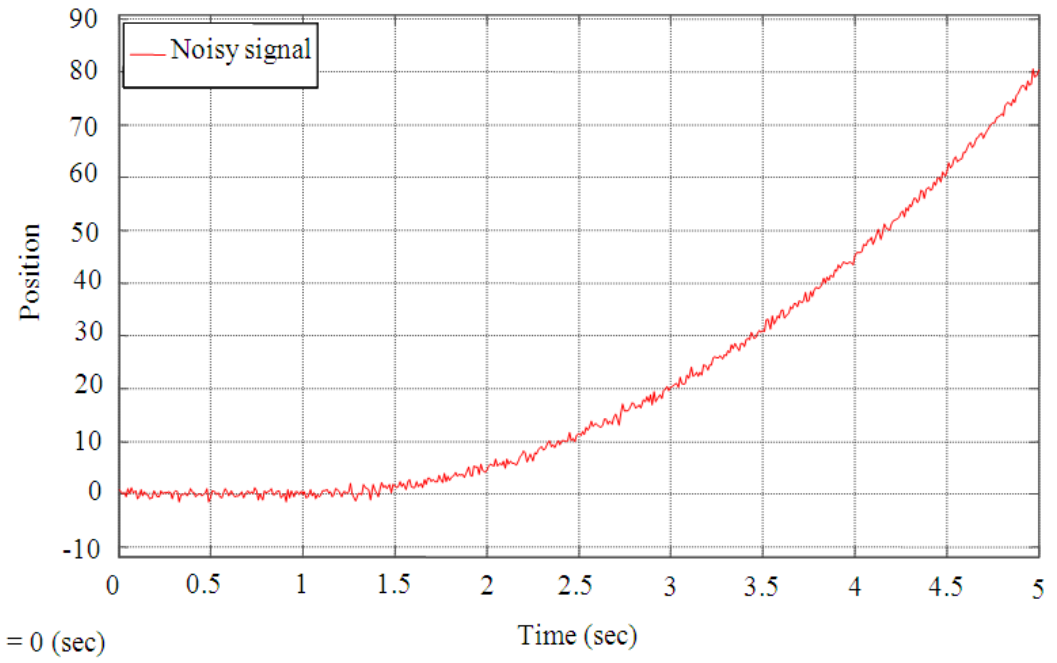

Fig. 12. Noise signal

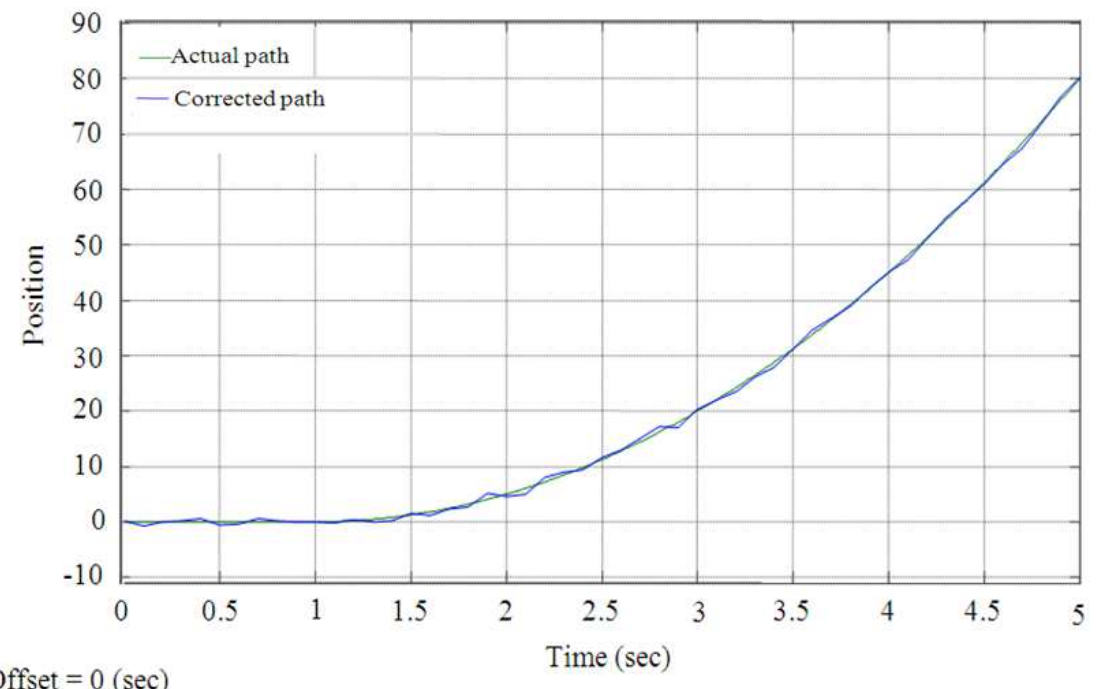

Fig. 13. Noise rejection by using EKF

Table 1. Parameters of Quad-rotor

\begin{tabular}{llll}
\hline Parameter Name & Symbol & Value & Unit \\
\hline $\begin{array}{l}\text { Rotational Inertia } \\
\text { along Z-axis }\end{array}$ & $\mathrm{I}_{\mathrm{zz}}$ & 0.0017 & $\mathrm{~kg} \cdot \mathrm{m}^{2}$ \\
$\begin{array}{l}\text { Rotational Inertia } \\
\text { along X-axis }\end{array}$ & $\mathrm{I}_{\mathrm{xx}}$ & 0.0021 & $\mathrm{~kg} \cdot \mathrm{m}^{2}$ \\
$\begin{array}{l}\text { Rotational Inertia } \\
\text { along X-axis }\end{array}$ & $\mathrm{I}$ & 0.0021 & $\mathrm{~kg} . \mathrm{m}^{2}$ \\
Total Mass & $\mathrm{m}$ & 0.65 & $\mathrm{~kg}$ \\
Thrust Constant & $\mathrm{b}$ & $\mathrm{N} . \mathrm{s} 2$ & $\mathrm{~N} . \mathrm{s}^{2}$ \\
$\begin{array}{l}\text { Drag Constant } \\
\text { Arm Length }\end{array}$ & $\mathrm{d}$ & $7.50 \mathrm{e}-7$ & $\mathrm{~N} . \mathrm{s}^{2}$ \\
\hline
\end{tabular}


During simulation in proposed PID controller, 0 set points is set for each attitude angle (Yaw, Pitch and Roll) for maintaining Quad-rotor attitude under disturbance and noisy conditions. Figure 5 shows, the simulation results of quad-rotor while hovering in $\mathrm{Z}$ position with amplitude of 10 . The altitude controller quickly stabilize the quad-rotor and only takes settling time of 3.8 second when PID controller is auto-tuned with parameter of Kp $=0.738, \mathrm{Ki}=0.0078, \mathrm{Kd}=0.0086$.

Figure 6, 8 and 10 demonstrates that the disturbance is added with different interval of time and its effect on Roll angle, Pitch Angle and Yaw angle respectively. Figure 7, 9 and 11 shows the simulation results of complete attitude stabilization of quad-rotor. These results proved that, the proposed PID controller work very well and easily handled the disturbance condition and quickly stabilized the quad-rotor attitude. The autotuned chosen PID Parameters for attitude controller are $\mathrm{Kp}=0.1198, \mathrm{Ki}=0.0009, \mathrm{Kd}=0.1382$.

Figure 12 shows the effect of Gaussian noise (with variance of approximately $0.4 \mathrm{~m} / \mathrm{s}$ ) when added in actual trajectory path and to evaluate the performance of EKF (Fig. 13) shows the actual and measured path of the particular system with the rejection of noise.

\section{CONCLUSION}

This study presents the successful simulation validation of proposed controller for altitude and attitude stabilization of Quad-rotor UAV system under disturbance condition. With Lyapunov stability theorem it is proved that system altitude parameters are globally stable. The parameters of proposed PID controller are selected by PID auto-tune method. Finally EKF is introduced by which the estimates of parameters could converge successfully with their right value at the time of the desired exit is deductible under the terms of the difficulties due to the noise. According to simulations, there is evidence that the effectiveness of the control method is verified that the controller has offered to return the entire system to stabilize the situation where there is any kind of disturbance and noise imposed on quad-rotor. From the simulations it is proved that the effectiveness of control method is verified.

\section{REFERENCES}

Becker, M., R.C.B. Sampaio, S. Bouabdallah, V.D. Perrot and R. Siegwart, 2012. In flight collision avoidance for a Mini-UAV robot based on onboard sensors. Mechatronics Lab.
Chowdhury, A.B., A. Kulhare and G. Raina, 2012. A generalized control method for a Tilt-rotor UAV stabilization. Proceedings of the IEEE International Conference on Cyber Technology in Automation, Control and Intelligent Systems, May 27-31, IEEE Xplore Press, Bangkok, pp: 309-314. DOI: 10.1109/CYBER.2012.6392571

Gotbolt, B., N.I. Vitzilaios and A.F. Lynch, 2013. Experimental Validation of a Helicopter Autopilot Design using Model-Based PID Control. J. Intell. Robot. Syst., 70: 385-399. DOI: 10.1007/s10846012-9720-7

Hua, X., Y. Ruyi, Y. Jianqiang, F. Guoliang and J. Fengshui, 2011. Disturbance rejection in UAV's velocity and attitude control: Problems and solutions. Proceedings of the30th Chinese Control Conference, Jul. 22-24, IEEE Xplore Press, Yantai, pp: 6293-6298.

Jiao, Y., J. Du, X. Wang and R. Xie, 2010. Hœ state feedback control for UAV maneuver trajectory tracking. Proceedings of the International Conference on Intelligent Control and Information Processing, Aug. 13-15, IEEE Xplore Press, Dalian, pp: 253-257. DOI: 10.1109/ICICIP.2010.5564257

Lee, K.U., Y.H. Yun, W. Chang, J.B. Park and Y.H. Choi, 2011. Modeling and altitude control of quadrotor UAV. Proceedings of the 11th International Conference on Control, Automation and Systems, Oct. 26-29, IEEE Xplore Press, Gyeonggi-do, pp: 1897-1902.

Ryll, M., H.H. Bulthoff and P.R. Giordano, 2012. Modeling and control of a quadrotor UAV with tilting propellers. Proceedings of the IEEE International Conference on Robotics and Automation, May 14-18, IEEE Xplore press, Saint Paul, MN., pp. 4606-4613. DOI: 10.1109/ICRA.2012.6225129

Wang, Z., A. Behal, B. Xian and J. Chen, 2011. Lyapunov-based adaptive control design for a class of uncertain MIMO nonlinear systems. Proceedings of the IEEE International Symposium on Intelligent Control, Sep. 28-30, IEEE Xplore Press, Denver, CO., pp. 1510-1515. DOI: 10.1109/ISIC.2011.6045409

Zhang, J., G. Welch and G. Bishop, 2011. Power system state estimation with dynamic optimal measurement selection. Proceeding of the IEEE Symposium Computational Intelligence Applications in Smart Grid, Apr. 11-15, IEEE Xplore Press, Paris, pp: 1-6. DOI: 10.1109/CIASG.2011.5953339 